\title{
Improving Medical Practice: A Conceptual Framework
}

Leif I. Solberg, MD

HealthPartners Research Foundation, Minneapolis, Minn
Conflict of interest: none reported

\section{CORRESPONDING AUTHOR}

Leif I. Solberg, MD

HealthPartners Research Foundation PO Box 1524, MS21111R

Minneapolis, MN 55440

leif.i.solberg@healthpartners.com

\begin{abstract}
PURPOSE The purpose of this article is to produce a relatively simple conceptual framework for guiding and studying practice improvement.
\end{abstract}

METHODS I summarize the lessons from my experience with a variety of quality improvement research studies during the last 30 years, supplemented with relevant literature from both medicine and other industries about the issues associated with successful quality improvement.

RESULTS My experience suggests that organizational leadership with an urgent vision for change, ability to manage the change process, and selection of systematic changes capable of fulfilling the vision are each critical for successful quality improvement. Published literature from other industries emphasizes the importance of a goal-directed change process managed by leaders who recognize the need to engage their employees and other leaders in a disciplined but flexible way that accommodates external and internal factors and uses teams and group learning. It also suggests the importance of organizational context and the level of external and internal barriers and facilitators for change. The resulting model proposes that priority, change process, and care process content are necessary for measurable improvements in quality of care and patient outcomes, although internal and external barriers must also be attended to and addressed.

CONCLUSION This framework may provide a guide to those in the front lines of care who would like to make the care transformations that are needed to greatly improve care. It may also be helpful to those who are developing or testing interventions and recruiting medical practices for such change efforts.

Ann Fam Med 2007;5:251-256. DOI: 10.1370/afm.666.

\section{INTRODUCTION}

rossing the Quality Chasm, the landmark 2001 report from the Institute of Medicine (IOM), crystallized and dramatized the challenge facing American medicine by pointing out that incremental improvement was inadequate: "[B]etween the health care we have and the care we could have lies not just a gap, but a chasm." ${ }^{.1}$ This report, along with the earlier IOM report on medical errors, also highlighted the need to change the environment in which health care professionals provide care. ${ }^{2}$ Both reports clearly recognized the quality chasm as a problem of systems, not people.

As with most paradigm shifts, these recommendations didn't come from nowhere. They were built on a growing body of research evidence about the inexplicable geographic variations in care, the inadequate implementation of evidence-based guidelines, and the need to shift from single interventions to change the behavior of individual physicians to focus instead on the practice systems and organizations in which physicians work..$^{3-8}$

Although there has been slow improvement in care quality, especially for some chronic conditions, the reports have not yet led to the dramatic improvements they called for. I suspect that this lack of improvement is due partly to the time needed for realignment of financial incentives and widespread acceptance of the need for change, and partly to continuing uncertainty 
among medical practices about what to change and how to change it. The Chronic Care Model (CCM) is increasingly accepted now as a conceptual framework for what needs changing, not only for chronic conditions, but also for acute and preventive care. ${ }^{9,10}$ Similarly, the Model for Improvement is seen as an advance from the earlier Continuous Quality Improvement and Total Quality Management approaches to how to make change, and regional or national collaboratives provide a way to facilitate its implementation. ${ }^{11-13}$ Neither of these models, however, has penetrated widely into the small- to medium-sized medical practices that provide the great majority of medical care in the United States. They are also often seen as separate and conflicting, rather than complementary, approaches to improvement. So, if medical practice is to be transformed, it might be helpful to the physician and administrative leaders of that effort to have a relatively simple conceptual framework that shows how these models fit together in relation to other important factors.

To construct such a framework, I have relied on several sources. First are the lessons from my experience during the past 35 years in both practice redesign efforts and many research trials or studies of quality improvement efforts. Second is a growing and important literature on organizational change and quality improvement, both in medical care and in other industries. Finally, the 2 articles our research group published recently in this journal used a multimethod approach ${ }^{14,15}$ to studying an attempt by one large multispecialty medical group to implement the CCM. ${ }^{16,17}$ Those articles provide a current illustration of the framework.

It is hard to identify a specific conceptual starting point for this framework, because the ideas the CCM articles reflect have built slowly for many years. The ideas have developed primarily because most of my research trials have combined quantitative and qualitative methods, providing needed deeper information about how and why the care process changes occurred (or did not). But they also developed from the group reflection that was driven by the fact that most of those trials did not produce the degree of quantitative changes expected. I can truly verify there may be more learning from failures than from successes. The 2 recently-published studies provide especially rich fodder for reflection and for further extending an understanding of change efforts, while also providing an opportunity to demonstrate example details. I recognize that the individual ideas in the framework described here are not new, but I hoped to bring them together in a coherent way that is simple enough to serve as a guide for those wishing to transform care or study improvement efforts without elaborating all the complexities of most other models that tend to serve as roadblocks to action.

\section{EXPERIENCE}

For many years, I have been intensively involved in both applied research and personal practice change efforts, culminating during the past 5 years in an intensive observational study of the transformational change efforts of a large multispecialty medical group. ${ }^{16,18-22}$ Fortunately, that study was supplemented by studying the approach to change by a small and exemplary family practice group. ${ }^{21}$ Some of my previous experiences that are especially worth highlighting follow.

IMPROVE was a randomized controlled trial in 44 primary care practices of an intervention designed to teach early Continuous Quality Improvement methods and systems content for improving the delivery of 8 preventive services. ${ }^{22}$ Although it failed to show greater improvement in service rates in the intervention arm during the 2 years of the trial, most of the subject practices were enthusiastic about what they had learned, and many other practices subsequently requested similar training. Many local leaders would today credit the understanding of systems thinking and planned change that started with IMPROVE for the unusually high quality of care in this region. ${ }^{23,24}$ This effort may have failed quantitatively in part because of the short research timeline, but it was also clear that there had been inadequate motivation for change, organizational ability to manage change, choice of targeted change content, and use of the recommended change process. ${ }^{25}$

IDEAL was a nearly simultaneous but smaller randomized trial of similar methods to improve diabetes care. ${ }^{26}$ This trial showed improvements in care processes, but not outcomes, in part because of limited practice leadership support, but also because the intervention also may not have emphasized the right types of care changes. ${ }^{27}$

DIAMOND tested a more current version of quality improvement for depression care in a controlled trial that worked well, but had no effect because it did not have sufficient leadership support and still required that individual physicians initiate the new care process, so most patients were uninvolved. ${ }^{28,29}$ Wagner, in an accompanying editorial, ${ }^{30}$ said that "the elegant failure of Solberg and colleagues should be required reading," demonstrating that strong leadership and "fundamental system change affecting the care of all patients" was essential.

Our studies of our HealthPartners Medical Group's earlier very successful implementation of an advanced access scheduling system reinforced the importance of priority, strong medical group leadership, and a clear collaborative change process (both centrally and at individual clinics). ${ }^{19}$ It also reinforced the importance of paying attention to both concurrent changes and to various barriers and facilitators, from clinic demand- 
capacity ratios to the mental models, practice styles, and work effects for individual physicians.

In each of these studies, our research team used quantitative and qualitative methods to best understand what happened in the change effort. This background has been invaluable and perhaps essential for an ability to draw lessons from both successes and failures. I have also been integrally involved in the front lines of each change, so personal awareness and reflection could be added to the more objective analyses as observers.

\section{LITERATURE}

The bulk of relevant organizational change and quality improvement literature from other industries consists of case studies or prescriptions from consultants or participants in the drive to make various businesses more successful in economic and quality terms. In the last 50 years, these authors have included such quality gurus as Deming and Juran, as well as a host of management experts. ${ }^{31,32}$ Their principal messages have been addressed to organizational leaders as the main agents of change. Their recommendations can be divided into those that favor a "hard," or theory E, approach that focuses on economic value through dramatic structural changes, and a "soft," or theory $\mathrm{O}$, approach that instead aims to develop the right organizational culture and human capability. ${ }^{33}$ Most successful examples, however, have included some use of both approaches.

For health care, some of the most salient lessons from other industries have come from those emphasizing the softer approach. For example, one leading writer on managing change, Kotter, emphasizes the importance of having vision, strategy, a guiding coalition with a sense of urgency, excellent communication, and widespread empowerment. ${ }^{14,15}$ Senge and colleagues put that change management approach in context by identifying the essential need to understand and use 5 disciplines: personal mastery, mental models, shared vision, team learning, and, most importantly, systems thinking (which integrates the other 4). ${ }^{34,35}$ Finally, Collins, is one of the very few to use a formal group-research process to identify the characteristics of companies that succeed economically over the long term. In Good to Great he emphasizes the need for discipline in companies that are successful. ${ }^{36}$ The key factors he identifies include disciplined but not charismatic or authoritarian leaders at all levels that fit the vision, disciplined thought to face brutal facts and support the central "hedgehog concept" of the company, and disciplined action that uses technology selectively to accelerate momentum.

Moving from the literature of other industries to health care, Koeck has noted that "[a] student of management and organization theory could only be stunned by how little the efforts to improve quality [in health care] have learnt from current thinking in management and from the experience of other industries." ${ }^{17}$ An overview of how this literature applies in health care by Ferlie et $\mathrm{al}^{5}$ emphasizes the rise of management that provides a challenge to previous clinical domination, the need to respond to a market as other industries must, and the need for understanding how to manage change. Rhydderch et $\mathrm{al}^{38}$ summarize the "big 4" organizational theories in health care that can help general practice respond to the quality problems caused by system failures:

1. Systems theory, which sees practices as inertial and change as intentional, taking place at the level of a single organization and using clear goals and standards, measurement, and feedback loops to guide change ${ }^{39}$

2. Organizational development theory, which shares most of the systems perspective, but adds that improvement is a process of planned change which depends on agreement between individual and organizational goals and which uses empowered practice teams to solve problems ${ }^{40}$

3. Complexity theory, which sees practices as complex adaptive systems, where change evolves from the interaction of individual agents with the external environment in an unending way and the emphasis is on continuous organizational learning rather than discrete projects ${ }^{41,42}$

4. Social worlds theory, which shares much of complexity's metaphor and analytic framework, but sees change as a negotiation between 2 or more social worlds where the direction is driven by opportunities for congruence

Garside $^{40}$ has done a particularly good job of addressing Koeck's concern, reviewing the literature and making specific recommendations. First, she highlights the need for a vision that is clearly articulated and strongly committed to the desired end state through the inevitable resistances that will develop. Second, she notes the necessity of an organizational culture that is supportive of the change direction. To create and sustain such a culture, leaders and organizational policies must work at effective communication, training, and staff involvement and engagement in the change process. Finally, she emphasizes that implementation must be managed well with effective project leaders and multidisciplinary team planning to provide some early successes while recognizing major change takes time and resources.

What I take from all these mostly synergistic lessons from the literature in other industries and in health care is that almost all (except for the complexity advocates) see change as a goal-directed process managed by leaders who recognize the need to engage their employees 
and other leaders in a disciplined but flexible way that accommodates external and internal factors and uses teams and group learning to create vision and manage change. Importantly, the change process they all focus on is separate from the actual changes needed and requires considerable attention, time, and resources. For an example of a practice change model based on complexity theory, see the model of Cohen et al. ${ }^{43}$

\section{A FRAMEWORK FOR IMPROVING MEDICAL PRACTICE}

From this web of personal experiences and the literature a basically simple framework for change has evolved for me, one that can help practices of any size keep an eye on the forest while still being capable of attending to the trees: the inherently complex details and confounding factors. This framework (Figure 1) focuses on the 3 main elements that must all be present to a substantial degree so that desired improvements in the quality of care processes and patient outcomes can be produced: priority, change process capability, and care process content. A particularly important feature of this framework is its emphasis on a clear separation of the change process from the care process content. This distinction is one that seems to be missing in most efforts to improve care. For example, the CCM itself notably does not include any dimension for how to implement its elements, so it should be seen as only providing guidance for the care process portion of the framework.

\section{Priority}

As with any major behavior change for an individual (smoking cessation, weight loss), it seems obvious that unless there is strong desire and resource allocation for the specific change, as well as freedom from competing or more important priorities, major change is unlikely to happen. Every source noted above identifies the importance of this factor, either explicitly or implicitly. At the same time, it is clearly not enough for top leaders to say that a particular change is a priority; that priority must be shared by other personnel at all levels and reinforced by focused actions and commitment of resources. The equivalent of a burning platform may be the best metaphor for this factor.

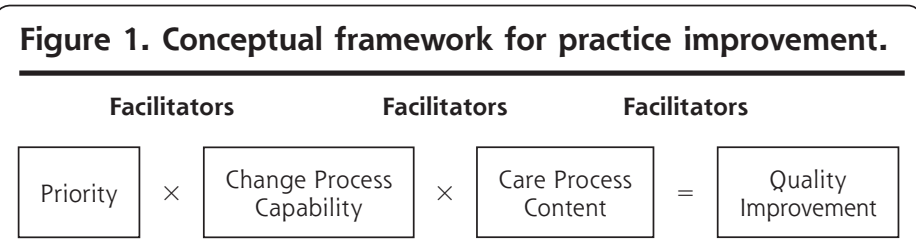

Barriers

Barriers

Barriers

\section{Change Process Capability}

Strangely, this factor important to improvement may be the least mentioned. The Institute for Healthcare Improvement has done a good job of highlighting its importance and, through the Model for Improvement, identifying a framework for thinking about the steps involved. ${ }^{12}$ Our research team's work with "insightful implementers" who have had successful improvement experience in various medical groups has helped to identify many of the factors involved in this capability, as well as additional useful strategies. ${ }^{44}$ The qualitative study of HealthPartners Medical Group's change efforts suggests that at least the following factors are important ${ }^{17}$ :

1. Strong effective leadership, both centrally and locally

2. Commonly understood framework and infrastructure for managing the change process

3. People at all levels with change management skills

4. Adequate resources and time devoted to the change process

5. A mature and capable clinical information system

6. Good communication and measurement skills

7. A high degree of trust and teamwork

8. Individual accountability

9. A high degree of involvement and engagement by personnel at all levels

\section{Care Process Content}

Although the CCM is vague about the exact nature of the care process changes to be made, it does emphasize systems-level changes in the practice environment rather than asking individuals to simply do better or to do things unlikely for human beings (such as having perfect memory or completely consistent actions). Many care process examples identified within the 6 elements of the CCM have moderate to good evidence of effectiveness in studies of those individual components, at least those that fit within the 4 elements of delivery system redesign, self-management support, decision support, and clinical information system. ${ }^{45-49}$

Depending upon the degree to which the 3 factors in my framework are present, a medical group or practice will be able to develop, implement, and sustain improved care quality for its patients, measurable by both improved services and improved patient outcomes. Ideally, this result would include all 6 domains of the IOM definition of quality.

The quantitative and qualitative papers that report the study of the HealthPartners Medical Group's efforts to implement the CCM help to illuminate that framework. ${ }^{16,17}$ While our quantitative study needed to restrict its scope to a focus on effectiveness 
measures, it showed that there were some improvements in some care processes and patient outcomes for patients with diabetes, heart disease, or depression. Measures of other processes and outcomes did not improve, however, especially for depression. This mixed outcome might have been predicted by the problems identified by the qualitative study, since there were deficiencies in each of the 3 factors in the conceptual framework.

Of course, an improvement effort does not take place in a vacuum. There are a great many other factors, both internal and external to a practice, that serve as facilitators and barriers. For example, organizational priority is clearly facilitated not only by external incentives or penalties, competition, and key customers, but also by such internal factors as competing priorities and the mission (whether articulated or not). Change process capability requires adequate resources, skilled people, a supportive culture, an understanding of measurement and systems, clinician champions, and a capable clinical information system. Effective care processes are facilitated by the existence of other practice systems and support for care standardization, team care, population management, and patient-centeredness. The absence of these facilitators becomes barriers.

Others have identified additional factors that appear to have an effect on either the priority or the capability of a care system to improve quality. For example, Bodenheimer et al, in their qualitative study of 158 leaders of varied care delivery systems nationally, found that the most commonly mentioned barriers were poor financial situation, reimbursement that does not reward high quality, inadequate information technology, physician resistance, and physicians that were too busy. ${ }^{50}$ The two most commonly mentioned facilitators in that study were strong leadership and an organizational culture that valued quality. Other quantitative results from a related study of 1,104 care systems found that factors positively associated with offering health promotion programs included outside reporting of quality measures, public recognition for quality measure success, clinical information technology systems, being a medical group, and ownership by a hospital or health plan. ${ }^{51}$

To improve care, each of the 3 main factors must be addressed in an overall environment that minimizes barriers while it maximizes facilitators. Of course, if any of the 3 factors is missing or of limited strength, or if there are major barriers, little will happen or the change will not be sustained, which has been the case for most improvement efforts. In such a case, the framework should be helpful to those interested in change. First, by assessing each of the 3 factors, the main area to target should be clear. Then, by considering which of the barriers are most amenable to change, external or internal change agents may be able to affect that factor selectively. In the absence of external stimuli for affecting priority in a medical group lacking that factor, however, there may be little that can be done until such time as those stimuli develop or the organization enters a crisis that leads to new leadership with a different vision and sense of urgency.

Finally, how does this conceptual framework fit with the recommendations in the Future of Family Medicine report? Those recommendations could be seen as similar to the CCM in providing a vision for the elements of a desirable practice of the future. In that sense, they relate primarily to the care process content part of the framework. As with the CCM, however, they do not provide any guidance about the change process needed to achieve that vision or the factors important to stimulating the change (such as organizational priority), so they are important but incomplete.

Although this framework will not solve the national need to cross the quality chasm highlighted by the IOM reports, ${ }^{1}$ such a simpler framework can at least provide a clearer guide to those in the front lines of care who would like to make the care transformations that are needed. It can also be helpful to those who are developing or testing interventions and recruiting medical practices for such change efforts. Do the practices have sufficient priority for this change and will they have enough capability for managing the process of change? Have the best and most feasible care process targets been chosen for improvement? Are there internal or external barriers that will prevent success no matter how well the other stars are aligned? On the answers to these questions may rest the likelihood of a chasm-leaping transformation in medical practice.

To read or post commentaries in response to this article, see it online at http://www.annfammed.org/cgi/content/full/5/3/251.

Key words: Chronic disease; delivery of health care; disease management; models, organizational; quality of health care; physician's practice patterns; health services research

Submitted April 4, 2006; submitted, revised, September 28, 2006; accepted October 3, 2006.

Funding support: This article was supported by grant 041868 from the Robert Wood Johnson Foundation through the Improving Chronic Illness Care Initiative.

\section{References}

1. Institute of Medicine. Crossing the Quality Chasm: A New Health System for the 21st Century. Washington, DC: National Academy Press; 2001.

2. Institute of Medicine. To Err is Human. Washington, DC: National Academy Press; 1999.

3. Weiner JP, Parente ST, Garnick DW, Fowles J, Lawthers AG, Palmer RH. Variation in office-based quality. A claims-based profile of care provided to Medicare patients with diabetes. JAMA. 1995;273(19):1503-1508. 
4. Wennberg JE, Freeman JL, Culp WJ. Are hospital services rationed in New Haven or over-utilised in Boston? Lancet. 1987;1(8543):1185-1189.

5. Ferlie E, Fitzgerald L, Wood M. Getting evidence into clinical practice: an organisational behaviour perspective. J Health Serv Res Policy. 2000;5(2):96-102.

6. NHS Centre for Reviews and Dissemination. Getting evidence into practice. Eff Health Care. 1999;5(1):1-16.

7. Davis DA, Taylor-Vaisey A. Translating guidelines into practice. A systematic review of theoretic concepts, practical experience and research evidence in the adoption of clinical practice guidelines. CMAJ. 1997;157(4):408-416.

8. Sol berg LI. Guideline implementation: what the literature doesn't tell us. Jt Comm J Qual Improv. 2000;26(9):525-537.

9. Glasgow RE, Orleans CT, Wagner EH. Does the chronic care model serve also as a template for improving prevention? Milbank Q. 2001;79(4):579-612, iv-v.

10. Epping-Jordan JE, Pruitt SD, Bengoa R, Wagner EH. Improving the quality of health care for chronic conditions. Qual Saf Health Care. 2004;13(4):299-305.

11. Berwick DM. Developing and testing changes in delivery of care. Ann Intern Med. 15 1998;128(8):651-656.

12. Langley GJ, Nolan KM, Nolan TW, Norman CL, Provost LP. Improvement Guide: A Practical Approach to Enhancing Organizational Performance. San Francisco, Calif: Jossey-Bass; 1996.

13. Solberg LI. If you've seen one quality improvement collaborative. Ann Fam Med. 2005;3(3):198-199.

14. Borkan JM. Mixed methods studies: a foundation for primary care research. Ann Fam Med. 2004;2(1):4-6.

15. Creswell JW, Fetters MD, Ivankova NV. Designing a mixed methods study in primary care. Ann Fam Med. 2004;2(1):7-12.

16. Solberg LI, Crain AL, Sperl-Hillen JM, Hroscikoski MC, Engebretson $\mathrm{KI}$, O'Connor PJ. Care quality and implementation of the Chronic Care Model: a quantitative study. Ann Fam Med. 2006;4(4)310-316.

17. Hroscikoski MC, Solberg LI, Sperl-Hillen JM, Harper P, Crabtree BF. The challenges of change: a qualitative study of Chronic Care Model implementation. Ann Fam Med. 2006;4(4)317-326.

18. Solberg LI, Crain AL, Sperl-Hillen JM, Hroscikoski MC, Engebretson $\mathrm{KI}$, O'Connor P J. Effect of improved primary care access on quality of depression care. Ann Fam Med. 2006;4(1):69-74.

19. Solberg LI, Hroscikoski MC, Sperl-Hillen JM, O'Connor PJ, Crabtree $B F$. Key issues in transforming health care organizations for quality: the case of advanced access. Jt Comm J Qual Saf. 2004;30(1):15-24.

20. Solberg LI, Maciosek MV, Sperl-Hillen JM, et al. Does improved access to care affect utilization and costs for patients with chronic conditions? Am J Manag Care. 2004;10(10):717-722.

21. Solberg LI, Hroscikoski MC, Sperl-Hillen JM, Harper PH, Crabtree BF. Transforming medical care: Case study of an exemplar small medical group. Ann Fam Med. 2006;4(2):109-116.

22. Solberg LI, Kottke TE, Brekke ML, Calomeni CA, Conn SA, Davidson G. Using continuous quality improvement to increase preventive services in clinical practice-- LI, Zander KM. The failure of a controlled trial to improve depression care: a qualitative study. Jt Comm J Qual Improv. 2001;27(12):639-650.

23. Solberg LI, Kottke TE, Brekke ML, et al. Failure of a continuous qual ity improvement intervention to increase the delivery of preventive services. A randomized trial. Eff Clin Pract. 2000;3(3):105-115.

24. Fischer LR, Solberg LI, Kottke TE. Quality improvement in primary care clinics. Jt Comm J Qual Improv. 1998;24(7):361-370.

25. Solberg LI, Kottke TE, Brekke ML, Magnan S. Improving prevention is difficult. Eff Clin Pract. 2000;3(3):153-155.

26. Solberg LI, Reger LA, Pearson TL, et al. Using continuous quality improvement to improve diabetes care in populations: the IDEAL model. Improving care for Diabetics through Empowerment Active collaboration and Leadership. Jt Comm J Qual Improv. 1997;23(11):581-592.
27. O'Connor PJ, Desai J, Solberg LI, et al. Randomized trial of quality improvement intervention to improve diabetes care in primary care settings. Diabetes Care. 2005;28(8):1890-1897.

28. Fischer LR, Solberg LI, Zander KM. The failure of a controlled trial to improve depression care: a qualitative study. Jt Comm J Qual Improv. 2001;27(12):639-650.

29. Solberg LI, Fischer LR, Wei F, et al. A CQI intervention to change the care of depression: a controlled study. Eff Clin Pract. 2001;4(6):239-249.

30. Wagner EH. Quality improvement can't be optional. Eff Clin Pract. 2001;4(6):278-280.

31. Deming WE. The New Economics. Cambridge: Massachusetts Institute of Technology; 1994.

32. Juran JM. Juran on Leadership for Quality: An Executive Handbook. New York, NY: The Free Press (Macmillan); 1989.

33. Beer M, Nohria N. Cracking the code of change. Harv Bus Rev. 2000 2000;78(3):133-141.

34. Senge PM. The Fifth Discipline: The Art \& Practice of the Learning Organization. New York, NY: Currency Doubleday; 1990.

35. Senge PM, Kleiner A, Roberts C, Ross R, Roth G, Smith B. The Dance of Change. New York, NY: Doubleday; 1999.

36. Collins J. Good to Great. New York, NY: HarperCollins Publishers Inc 2001.

37. Koeck C. Time for organisational development in healthcare organisations. Improving quality for patients means changing the organisation. BMJ. 1998;317(7168):1267-1268.

38. Rhydderch M, Elwyn G, Marshall M, Grol R. Organisational change theory and the use of indicators in general practice. Qual Saf Health Care. 2004;13(3):213-217.

39. Hellriegel D, Slocum JW, Woodman RW. Organizational Behavior. 6th ed. St. Paul, Minn: West Publishing; 1992.

40. Garside P. Organisational context for quality: lessons from the fields of organisational development and change management. Qual Health Care. 1998;7 Suppl:S8-15.

41. Crabtree BF, Miller WL, Stange KC. Understanding practice from the ground up. J Fam Pract. 2001;50(10):881-887.

42. Plsek P. Redesigning health care with insights from the science of complex adaptive systems. In: Crossing the Quality Chasm: A New Health System for the 21st Century. Washington, DC: National Academy Press; 2001:309-322.

43. Cohen D, McDaniel RR, Jr., Crabtree BF, et al. A practice change model for quality improvement in primary care practice. J Healthc Manag. 2004;49(3):155-168; discussion 169-170.

44. Solberg LI, Brekke ML, Fazio CJ, et al. Lessons from experienced guideline implementers: attend to many factors and use multiple strategies. Jt Comm J Qual Improv. 2000;26(4):171-188.

45. Bodenheimer T, Wagner EH, Grumbach K. Improving primary care for patients with chronic illness. JAMA. 2002;288(14):1775-1779.

46. Wagner EH, Austin BT, Von Korff M. Organizing care for patients with chronic illness. Milbank Q. 1996;74(4):511-544.

47. Bodenheimer T. Interventions to improve chronic illness care: evaluating their effectiveness. Dis Manag. 2003;6(2):63-71.

48. Feifer C, Ornstein SM, Nietert PJ, Jenkins RG. System supports for chronic illness care and their relationship to clinical outcomes. Top Health Inf Manage. 2001;22(2):65-72.

49. Tsai AC, Morton SC, Mangione CM, Keeler EB. A meta-analysis of interventions to improve care for chronic illnesses. Am J Man Care. 2005;11:478-488.

50. Bodenheimer T, Wang MC, Rundall TG, et al. What are the facilitators and barriers in physician organizations' use of care management processes? Jt Comm J Qual Saf. 2004;30(9):505-514.

51. McMenamin SB, Schmittdiel J, Halpin HA, Gillies R, Rundall TG, Shortell SM. Health promotion in physician organizations: results from a national study. Am J Prev Med. 2004;26(4):259-264. 